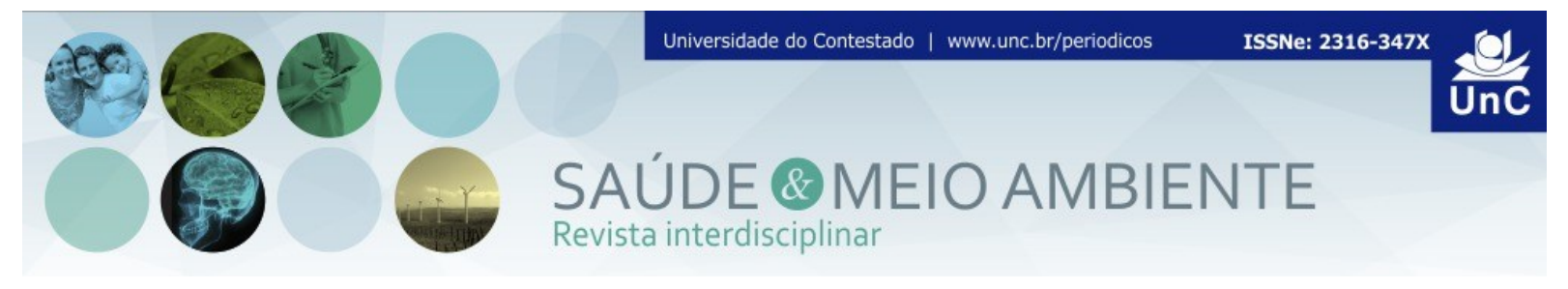

\title{
CONTROLE SOCIAL: REALIDADE DE UM MUNICÍPIO DO MEIO OESTE CATARINENSE
}

\author{
Janaina Morostica ${ }^{1}$ \\ Lilian Amorim ${ }^{2}$ \\ Maria Odete Amorim Mendes ${ }^{3}$ \\ Vilma Beltrame ${ }^{4}$
}

\begin{abstract}
RESUMO: Este estudo de caso teve por objetivo analisar as propostas aprovadas na $3^{a}$ Conferência Municipal de Saúde do município de Joaçaba, localizado no MeioOeste de Santa Catarina, e relacioná-las com o que foi proposto no Plano Municipal de Saúde realizado no mesmo período. Os dados mostraram que não há relação entre as propostas aprovadas na conferência e o conteúdo do Plano Municipal de Saúde e que, linguisticamente, algumas propostas não possuem nexo.Conclui-se que apesar da importância da confência Municipal de Saúde e do Plano Municipal de Saúde para a elaboração de políticas públicas coerentes com as necessidades da população e de ser tão bem embasado legalmente, o controle social, representado pelo conselho e conferência de saúde, ainda encontra dificuldade no desempenho de suas funções.
\end{abstract}

Palavras-chave: Participação Social. Política de Saúde. Conferência de Saúde.

\section{SOCIAL CONTROL: THE REALITY OF A CITY IN THE MIDWEST OF SANTA CATARINA}

ABSTRACT: This case study aiming to analyze the proposals approved at the 3rd Municipal Health Conference of Joaçaba and their insertion in the Municipal Health Plan in the same period. Data analysis was made after careful reading of the documents provided by the President of the Municipal Council of Health. Data analysis showed that there is no relationship between the proposals approved at the conference and the content of the municipal health plan and that, linguistically, some proposals are meaningless. We conclude that despite the importance of Municipal Conference of Health and the Municipal Health Plan for the development of public policies consistent with the population's needs and be just as legally grounded, social control, represented by the council and health conference still finds difficulty in performing their functions.

Keywords: Social Participation. Health Policy. Health Conference.

\footnotetext{
${ }^{1}$ Mestrado em Biociências e Saúde. Universidade do Oeste de Santa Catarina. Santa Catarina, Brasil. Email: janamorostica@yahoo.com.br

${ }^{2}$ Mestrado em Biociências e Saúde. Universidade do Oeste de Santa Catarina. . Santa Catarina, Brasil. Email: liliantania@yahoo.com.br

${ }^{3}$ Especialização em Saúde da Família pela Universidade Federal de Santa Catarina, Brasil (2011). Estudante da Universidade do Oeste de Santa Catarina, Brasil. E-mail: mariaodetem@yahoo.com.br ${ }^{4}$ Doutorado em Gerontologia Biomédica pela Pontifícia Universidade Católica do Rio Grande do Sul, Brasil (2008). Professor titular da Universidade do Contestado, Brasil. E-mail: vilma.beltrame@unoesc.edu.br
}

Saúde Meio Ambient. v. 4, n. 1, p. 107-116, jan./jun. 2015 


\section{INTRODUÇÃO}

A participação popular é um marco da democracia brasileira, pois permite a elaboração de politicas públicas mais condizentes as necesssidades da sociedade e um maior controle dos gastos públicos.

Umas das formas de controle social são as conferências municipais de saúde, espaços democráticos onde setores representativos da sociedade se reunem para elaborar propostas que contemplem as principais necessidades em saúde da população por eles representadas e que deveriam servir de base para a elaboração dos planos municipais de saúde.

O termo controle social é oriundo das ciências sociais e está relacionado às limitações das ações dos indivíduos baseadas nas normas, valores e comportamentos da sociedade à qual pertencem. Porém, no Brasil, após a promulgação da Constituição de 1988, o termo passou a representar uma diferente relação entre o Estado e a Sociedade, no qual cabe à sociedade o estabelecimento de práticas de vigilância e controle sobre o Estado. Foi a partir deste marco jurídico que foram instituídos espaços públicos para a participação da sociedade na elaboração das políticas públicas, através dos conselhos de saúde e da realização de conferências de saúde nas três esferas de governo (DALLARI; IANNI; OLIVEIRA, 2013; COSTA; PAIVA; STRALEN, 2014).

As Conferências e os Conselhos de Saúde são hoje os principais espaços de participação popular na elaboração de Políticas Públicas de Saúde (BRASIL, 2009a). A promulgação da lei $n^{\circ} 8.142$ em setembro de 1990 regulamentou esta participação da sociedade com a normatização dos Conselhos e das Conferências de Saúde o que veio a reforçar que só é possível abordar de forma eficiente os problemas de saúde do país quando a população participa na elaboração das políticas (BRASIL, 1990).

Segundo Schommer, Dahmer e Spaniol (2014) a partir da década de 1980 a sociedade civil ganha mais destaque nos meios políticos, o estado deixa de ser tão paternalista e autoritário, surgem novas formas de representação e se reconhece que o cidadão deve ser participativo e juntamente com o estado, responsável pela elaboração das políticas públicas.

As Conferências de Saúde são espaços legais e democráticos. Nelas, o povo pode e deve se manifestar, orientar e decidir os rumos da saúde em cada esfera de governo. As Conferências Municipais de Saúde demostram o compromisso do gestor com os necessários avanços no setor de saúde. Elas têm como objetivo: avaliar e propor diretrizes da política para o setor saúde, estabelecidas pelo Conselho Nacional de Saúde; discutir temas específicos para propor novas diretrizes locais da política de saúde e eleger os delegados para as Conferências Estaduais e Nacionais, quando for o caso (CONASEMS, 2013b).

Outra importante forma de controle social no SUS é a elaboração dos Planos Municipais de Saúde. Entre os marcos jurídicos que Ihe dão sustentação, a Lei 
8080/90 estabelece que: "os Planos de Saúde serão a base das atividades e programações de cada nível de direção do SUS" (BRASIL, 1990), e a Portaria n 3.332/2006, que firma o Plano de Saúde como instrumento de planejamento que "apresenta as intenções e os resultados a serem buscados [...], expressos em objetivos, diretrizes e metas".

A realização do Plano Municipal de Saúde colabora para a efetivação da descentralização preconizada pelo SUS. Deve acontecer no último ano de cada administração a partir de uma análise situacional, e objetiva definir intenções e resultados a serem buscados nos próximos quatro anos (BRASIL, 2009b).

A definição das diretrizes para a elaboração dos Planos de Saúde nos municípios cabe aos Conselhos Municipais de Saúde. Cabe também a este órgão deliberativo aprovar o Plano Anual de Gestão, verificar a movimentação dos recursos, fiscalizar os gastos e analizar contratos e convênios relacionados à saúde. Outra função dos conselhos é promover a educação da população para exercer o controle social (OLIVEIRA, 2007).

O objetivo deste estudo de caso foi verificar se as ações propostas no plano municipal de saúde para o período 2010/2013 contemplavam as necessidades elencadas durante a $3^{a}$ Conferência Municipal de Saúde do município de Joaçaba, realizada no ano de 2011.

\section{METODOLOGIA}

Trata-se de um estudo de caso com o objetivo de analisar as propostas aprovadas na $3^{a}$ Conferência Municipal de Saúde do município de Joaçaba, e relacioná-las com as ações propostas no Plano Municipal de Saúde. O estudo foi baseado nos relatórios finais destes dois eventos. Foi realizada uma leitura minuciosa de cada documento e as propostas aprovadas foram analisadas e comparadas com as ações do Plano Municipal de Saúde.

\section{RESULTADOS E DISCUSSÃO}

A $3^{a}$ Conferência Municipal de Saúde do Município de Joaçaba teve participantes representantes do governo (gestores), prestadores de serviços de saúde, profissionais de saúde e usuários. Teve como tema central: "Todos usam o SUS! SUS na Seguridade Social, política pública, patrimônio do povo brasileiro".

Foram aprovadas propostas relacionadas a três eixos na Conferência: 
Eixo 1 - Política de Saúde e na Seguridade Social

1. Ampliar a oferta de serviços especializados gratuitos no município;

2. Melhorar o sistema de informação sobre os serviços do SUS;

3. Melhorar o acolhimento no tempo adequado no SUS;

4. Informar melhor a população sobre a integração entre as políticas de saúde com as outras políticas de seguridade social;

5. Melhorar o acolhimento e organização da atenção básica;

6. Melhorar a reabilitação em saúde;

7. Implantação do NASF;

8. Implantação do prontuário eletrônico melhorando a eficiência no atendimento e registro;

9. Estruturação de recursos humanos e físicos nos serviços de vigilância sanitária, nutricional, epidemiológica e ambiental.

Eixo 2 - Participação e Controle Social:

1. Criar conselhos comunitários de saúde;

2. Criar programa municipal de educação continuada aos profissionais e educação em saúde aos usuários.

Eixo 3 - Gestão no SUS:

1. Investir na aquisição e qualificação profissional nas mais diversas áreas;

2. Melhorar a comunicação entre os setores, usuários e profissionais;

3. Investir na melhoria das campanhas de saúde relacionadas à mulher, ao homem, aos idosos e às crianças;

4. Flexibilizar a lista de itens de medicação da farmácia básica;

5. Garantir o fornecimento dos medicamentos contidos na lista da farmácia básica aos usuários de todos os serviços do SUS (ESFs, emergência e urgência);

6. Ampliar as especialidades e procedimentos de profissionais conveniados ao SUS;

7. Implantar atendimento médico e odontológico de média complexidade no município;

8. Garantir o atendimento de média e alta complexidade mantendo as especialidades obrigatórias nos serviços de urgência e emergência (clínica médica, cirúrgica, pediatria, neurologia, ortopedia, ginecoobstetrícia e anestesia);

9. Implantação de unidade de Pronto Atendimento regional;

10. Flexibilizar os horários dos atendimentos nos ESFs.

O Plano Municipal de Saúde do município de Joaçaba foi elaborado nos meses de novembro e dezembro de 2009 e abrange o período de janeiro de 2010 a 
dezembro de 2013. Segundo seu relatório teve como meta a melhoria da qualidade dos serviços prestados, refletindo assim na qualidade de vida dos usuários do SUS (JOAÇABA, 2009). De forma reduzida e esquemática as estratégias de ação elencadas no Plano Municipal de Saúde foram:

Prioridades e estratégias de ação:

1. Serviço de atenção à mulher;

2. Promover educação permanente em saúde;

3. Grupo de gestantes;

4. Melhorar a cobertura do pré-natal;

5. Aumentar a cobertura de vacinação dos idosos (Infuenza) até atingir a meta do Ministério da Saúde;

6. Facilitar o diagnóstico precoce dos casos confirmados de câncer;

7. Instalar sistema de referência e contra-referência;

8. Criar protocolos de atendimento de médicos e enfermagem; e aprovação dos mesmos pela câmara de vereadores;

9. Melhorar a capacidade de enfrentamento a doenças emergentes e endemias;

10. Educação continuada sobre a dengue;

11. Implantar o projeto de zoonoses;

12. Programar saúde do adolescente;

13. Promover campanhas educativas na saúde bucal.

Determinantes e condicionantes de saúde:

1. Ampliar a rede e saneamento básico.

Gestão em saúde:

2. Ampliar o fornecimento de medicação;

3. Saúde do trabalhador;

4. Reformas com ampliação das sedes próprias das ESFs;

5. Implantação do CAPS AD;

6. Implantar banco de coleta de dados e sistema de informatização na Secretaria Municipal de Saúde;

7. Construir sedes próprias para as unidades de saúde da família, nos bairros onde a secretaria já possui terreno;

8. Adquirir terreno para construção de unidades de saúde da família;

9. Aquisição de equipamentos e móveis para as unidades;

10. Implantar sistema de monitoramento, regulação, controle e avaliação;

11. Instalar ambulatório médico de especialidade;

12. Estruturar um espaço para a biblioteca informativa;

13. Criar Núcleo de Apoio à Saúde da Família (NASF). 
Joaçaba é um município do meio-oeste de Santa Catarina, com uma população estimada de 27.020 habitantes de acordo com o IBGE/2014, sua economia é baseada no comércio e na indústria. É considerada referência regional em saúde e sede da $8^{a}$ Gerência Regional de Saúde das Secretarias de Estado de Desenvolvimento Regional.

A análise do relatório final da $3^{a}$ Conferência Municipal de Joaçaba mostra que ela foi convocada e realizada de acordo com as normas do CONASEMS. Embora a conferência tenha seguido o tema proposto pelo Ministério da Saúde e os grupos de trabalho tenham sido divididos segundo os eixos determinados, percebeuse que as propostas sugeridas não eram coerentes com o tema. Cada um dos três eixos possuía diversas diretrizes, para cada uma foram propostas ações. Percebeuse que algumas destas propostas eram confusas e que nem sempre as propostas sugeridas estavam relacionadas com sua respectiva diretriz. Como exemplo, podemos citar a terceira diretriz do primeiro eixo cujo enunciado era "Melhorar o acolhimento no tempo adequado no SUS" e teve como uma de suas propostas: "Agir com ética profissional adequada em todo processo de saúde" (JOAÇABA, 2011, p.18).

Apesar da importância do Controle Social e de o segundo eixo referir-se exclusivamente a ele, neste tópico foram elencadas apenas duas diretrizes: "Criar Conselhos Comunitários de Saúde" e "Criar Programa Municipal de Educação Continuada aos profissionais e educação em saúde e aos usuários". Conselhos comunitários necessitam de membros policamente articulados e conscientes dos problemas de suas comunidades o que não é a nossa realidade. Para termos conselhos efetivos a população precisa ser educada para entender quais os determinantes que atuam sobre as condições de saúde e ter noção de quais as medidas necessárias para resolver os problemas mais prevalentes em cada bairro ou comunidade. Educação demanda tempo, planejamento cuidadoso e recursos, por isso, num prazo de quatro anos fica difícil criar conselhos comunitários com uma atuação que impacte as condiçoes de sáude das comunidades. Além disso, a educação continuada dos profissionais de saúde tem sido feita de maneira muito esporádida e pontual. Isso demonstra que a sociedade como um todo ainda não entende o Controle Social como sendo a participação da sociedade na formulação, fiscalização e implementação da Política Municipal de Saúde.

Dallari et al.(2013) colocam que a participação social decorrente do processo de descentralização e redemocratização estabelecidas no país após 1988, esbarram em problemas históricos e socioculturais como a falta de tradição participativa, o autoritarismo do estado brasileiro e a cultura política vigente que não estimula a educação da população para uma participação mais efetiva no controle das políticas públicas. A falta de preparo dos participantes em formular propostas coerentes e voltadas para as reais necessidades da população reforça esta ideia.

Em 1946, a Organização Mundial de Saúde (OMS) passou a definir saúde como "situação de perfeito bem-estar físico, mental e social". Apesar de criticado por ser uma meta impossível de ser alcançada, este conceito representa um grande avanço, pois ao deixar de pensar saúde como sendo apenas a ausência de doença, 
fica implícito que para que as pessoas tenham saúde são necessárias ações de promoção e prevenção e não apenas ações curativas (FERRAZ; MARCO, 1997).

Observou-se que apesar desta evolução do conceito de saúde o enfoque da maioria das propostas aprovadas na conferência analisada tinha enfoque em ações curativas, o que demostra que os atores envolvidos na elaboração destas propostas continuam entendendo a saúde apenas como a ausência de doença (BACKES et al., 2009). Esta observação está de acordo com a pesquisa realizada por Chaves e Egry (2012), na qual os autores analisaram as Conferências do Município de Curitiba entre os anos 1997 e 2007 e concluíram que: não houve registros de propostas para intervenção nos processos determinantes do processo saúde-doença, não houve discussão sobre as condições de acesso aos serviços de sáude, sobre financiamento e sobre a necessidade de mudança no modelo de assistênciae que na maioria das conferências as discussões foram sobre os hábitos de vida dos pacientes e a não aderência aos tratamentos.

Ao relacionar o relatório final da Conferência Municipal com o do Plano Municipal de Saúde, percebe-se que apesar de ambos referirem-se ao mesmo período, eles não possuem relação alguma, o que demonstra que as pessoas envolvidas na realização da Conferência Municipal não se preocuparam em analisar o Plano de Saúde vigente. Diferentemente das propostas aprovadas na Conferência de Saúde, podemos observar no relatório do Plano Municipal diversas ações de promoção de saúde. Isto ocorre porque para a elaboração do Plano Municipal é realizada anteriormente uma análise situacional.

Entretanto o relatório final do Plano Municipal de Saúde, assim como o da Conferência Municipal, apresenta-se confuso e com alguns fragmentos de difícil compreensão. Podemos citar como exemplo a sexta estratégia de ação do Plano Municipal de Saúde de Joaçaba (2009, p.59), que assim se apresenta: "Facilitar o diagnóstico precoce dos casos confirmados de câncer". Para Baratieri, Freitas e Pilger (2013), esta dificuldade na elaboração do Plano Municipal pode estar relacionada à falta de conhecimento e preparo para a sua elaboração,da falta deorientação por parte de outras esferas e ao desconhecimento da importância deste instrumento para a gestão da saúde municipal.

Conforme citam Duarte e Machado (2012), o poder de decisão dos conselhos é ainda limitado, pois em cada município existem variáveis que facilitam ou que dificultam a efetiva participação social e ainda existem poucas estratégias para o monitoramento e avaliação das suas ações. Diegues (2012) afirma que os governos municipais devem estimular os cidadãos e a sociedade civil organizada para uma participação efetiva e não apenas simbólica na elaboração das políticas públicas, pautadas nas necessidades de cada região. 


\section{CONCLUSÃO}

A participação social é uma importante conquista da democracia, pois permite a elaboração de políticas públicas mais justas e adequadas à realidade de cada município. Contudo, o que se observa na maioria dos municípios brasileiros, principalmente os de pequeno e médio porte, é que nem a população nem os gestores tem consciencia desta importância. Estes instrumentos são elaborados apenas para o cumprimento de uma exigencia da lei e para garantir os repasses financeiros das esferas estadual e federal para os municípios na área da saúde.

Os gestores precisam perceber que as conferências e os planos sãoferramentas imprescindíveis para uma gestão em saúde de qualidade. É preciso divulgar para toda população o verdadeiro significado destes mecanismos decontrole social e despertar num maior número de pessoas as noções básicas de cidadania. Uma população consciente de seus direitos e deveres têm condições de participar de modo mais efetivo na construção das políticas públicas e de exigir dos políticos uma gestão mais eficiente. Enquanto não tivermos essa participaçao continuaremos tendo políticos descomprometidos, as conferências e planos continuarão não refletindo as reais necessidades em saúde dos municípios e a aplicação dos recursos financeiros em saúde contiuará sendo ineficiente.

\section{REFERÊNCIAS}

BACKES, Marli Terezinha Stein et al. Conceitos de saúde e doença ao longo da história sob o olhar epidemiológico e antropológico. Revista Enfermagem. UERJ, Rio de Janeiro, v. 1, n. 17, p.111-117, jan./mar. 2009. Disponível em: <http://www.facenf.uerj.br/v17n1/v17n1a21.pdf>. Acesso em: 27 jun. 2014.

BRASIL. Lei n 8.080 , de 19 de setembro de 1990. Dispõe sobre as condições para a promoção, proteção e recuperação da saúde, a organização e o funcionamento dos serviços correspondentes e dá outras providências. Diário Oficial da União, Brasília, DF. 1990a. Disponível em:

<http://www.planalto.gov.br/ccivil_03/leis//8080.htm>. Acesso em: 15 jun. 2014.

. Lei no 8.142 , de 28 de dezembro de 1990. Dispõe sobre a participação da comunidade na gestão do Sistema Único de Saúde (SUS) e sobre as transferências intergovernamentais de recursos financeiros na área da saúde. Diário Oficial da União, Brasília, DF. 1990b. Disponível em: <http://www.planalto.gov.br/ccivil_03/ leis//8142.htm>. Acesso em: 15 jun. 2014.

. Portaria $\mathrm{n}^{0} 3.332$, de 28 de dezembro de 2006. Aprova orientações gerais relativas aos instrumentos do Sistema de Planejamento do SUS. Diário Oficial da União. Brasília, DF. 2006. Disponível em: <http://bvsms.saude.gov.br/bvs/ saudelegis/gm/2006/prt3332_28_12_2006.html>. Acesso em: 15 jun. 2014. 
As Conferências Nacionais de Saúde: Evolução e Perspectivas. Conselho Nacional de Secretários de Saúde-CONASS,Brasília, DF. 100p. 2009a. Disponível em: <http://www.conass.org.br/conassdocumenta/cd_18.pdf>. Acesso em: 18 jun. 2014.

. Ministério da Saúde. Sistema de Planejamento do SUS (PlanejaSUS): uma construção coletiva - trajetória e orientações de operacionalização. Ministério da Saúde, Organização Pan-Americana de Saúde, Brasília, DF. 318 p.2009b. Disponível em: <http://bvsms.saude.gov.br/bvs/publicacoes/ planejaSUS_livro_1a6.pdf>. Acesso em: 18 jun. 2014.

CHAVES, Maria Marta Nolasco; EGRY, Emiko Yoshikawa. Conferências Municipais de Saúde: o movimento social organizado na construção de intervenções em saúde. Revista Escola Enfermagem USP, São Paulo, v. 6, n. 46, p.1423-1440, jun. 2012. Disponível em: <http://www.scielo.br/pdf/reeusp/v46n6/20.pdf>. Acesso em: 20 jun. 2014.

CONASEMS. Conselho Nacional de Secretarias Municipais de Saúde.Conferência Municipal de Saúde. Brasília, DF. 2013a. Disponível em:

<http://www.conasems.org.br/index.php/comunicacao/ultimas-noticias/2992pesquisa-conasems-conferencia-municipal-de-saude>. Acesso em: 20 jun.2014.

. Conselho Nacional de Secretarias Municipais de Saúde. Nota Técnica do

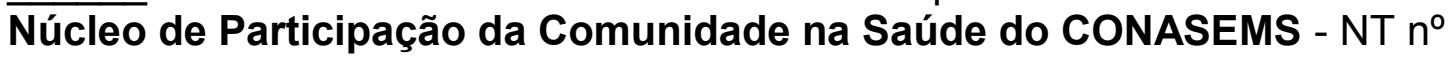
01/2013. Brasília, DF. 2013b. Disponível em: <http://www.conasems.org.br/ images/documents/2696/Nota\%20T\%C3\%A9cnica\%20-\%20Denise\%2001.pdf>. Acesso em: 21 jun. 2014.

. Conselho Nacional de Secretarias Municipais de Saúde.Nota Técnica do Núcleo de Participação da Comunidade na Saúde do CONASEMS - NT nº 02/2013. Brasília, DF.2013c. Disponível em: <http://www.conasems.org.br/ images/documents/2696/NT02-2013-v2-conferencias-municipais.pdf>. Acesso em: 21 jun. 2014.

DALLARI, Sueli Gandolfi; OLIVEIRA, Ana Maria Caldeira; IANNI, Aurea Maria Zöllner. Controle social no SUS: discurso, ação e reação. Ciência Saúde Coletiva, Rio de Janeiro, v. 18, n. 8, ago. 2013. Disponível em:<http://www.scielo.br/ scielo.php?script=sci_arttext\&pid=S1413-81232013000800017\&lng=pt\&nrm=iso>. Acesso em: 20 jun. 2014.

DIEGUES, Cesar Geraldo. A Construção da Participação Social na Gestão das Políticas Públicas: O Protagonismo do Governo Local no Brasil. Administração Pública e Gestão Social, Viçosa, v.4, n.4, p. 365-380. 2012. Disponível em: <http://www.apgs.ufv.br/index.php/apgs/article/view/115/199>. Acesso em: 20 jun. 2014. 
DUARTE, Elisfabio Brito; MACHADO, Maria de Fátima Antero Sousa. O exercício do controle social no âmbito do Conselho Municipal de Saúde de Canindé, CE. Saúde Soc., São Paulo, v. 21, supl. 1, mai. 2012. Disponível em:<http://www.scielo.br/ scielo.php?script=sci_arttext\&pid=S0104-12902012000500011\&Ing=en\&nrm=iso>. Acesso em: 15 jun. 2014.

FREITAS, Gleyce Mara; BARATIERI, Tatiane; PILGER, Calíope. Plano de saúde dos municípios de uma regional de saúde do Paraná. Revista de Enfermagem da EFSM, Cascavel, v. 1, n. 3, p.122-132, jan. 2013. Disponível em: <http://cascavel.ufsm.br/revistas/ojs-2.2.2/index.php/reufsm/about>. Acesso em: 20 jun. 2014.

JOAÇABA. Plano Municipal de Saúde 2010-2013. Secretaria Municipal de Saúde de Joaçaba, SC. 82 p. 2009.

$3^{a}$ Conferência Municipal de Saúde de Joaçaba- Relatório Final, 2011, Joaçaba/SC. 57 p. 2011.

OLIVEIRA, Flávia Silva de. Controle social no sistema único de saúde - SUS: aspectos constitucionais e legais dos Conselhos de Saúde. Prima Facie: Direito, História e Política, v. 22, n. 12, p.76-90, abr. 2013. Disponível em:

<http://periodicos.ufpb.br/ojs/index.php/primafacie/index>. Acesso em: 22 jun. 2014.

PAIVA, Fernando Santana de; STRALEN, Cornelis Johannes Van; COSTA, Pedro Henrique Antunes da. Participação social e saúde no Brasil: revisão sistemática sobre o tema. Ciênc. Saúde Coletiva,Rio de Janeiro, v. 19, n. 2, fev.2014. Disponível em <http://www.scielo.br/scielo.php?script=sci_arttext\&pid=S141381232014000200487\&Ing=pt\&nrm=iso>. Acessoem: 19 jun. 2014.

SEGRE, Marco; FERRAZ, Flávio Carvalho. O conceito de saúde. Revista Saúde Pública,São Paulo, v. 31, n. 5, out. 1997. Disponível em: <http://www.scielo.br/ scielo.php?script=sci_arttext\&pid=S0034-89101997000600016\&lng=pt\&nrm=iso>. Acesso em: 27 jun. 2014.

SCHOMMER, Paula Chies; DAHMER, Jeferson; SPANIOL, EnioLuiz.Controle Social no Brasil - Estadocêntrico ou Sociocêntrico? Evidências da $1^{\text {a }}$ Conferência Nacional sobre Transparência e Controle Social, Consocial. Administração Pública e Gestão Social,v. 1, n. 6, p.35-47, jan. 2014. Disponível em: <http://www.apgs.ufv.br/ index.php/apgs/article/view/578/328\#.VGel5MmxdCc>. Acesso em: 20 jun. 2014.

Artigo recebido em: 15/11/2014

Artigo aprovado em: 11/06/2015 